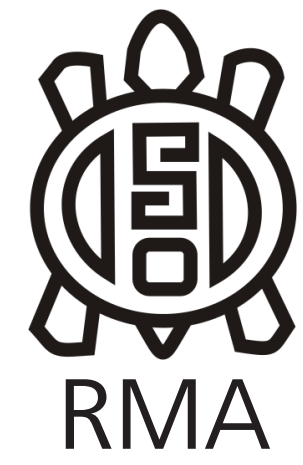

Arqueología

\title{
Médano Santa Clara medio siglo después (partido de Salliqueló, Campo de Dunas del Centro Pampeano): nuevas perspectivas de análisis del conjunto lítico
}

\author{
Médano Santa Clara half a century later (Salliqueló district, Central \\ Pampean Dunefields): new perspectives on the analysis \\ of the lithic assemblage
}

Florencia Santos Valero* y Pablo G. Messineo*

*INCUAPA-CONICET, Facultad de Ciencias Sociales, Universidad Nacional del Centro de la Provincia de Buenos Aires (UNICEN), Olavarría, Argentina.

E-mails: fsantosvalero@gmail.com y pmessine@soc.unicen.edu.ar

\begin{abstract}
Resumen
El siguiente artículo presenta el análisis tecnomorfológico de la colección lítica del sitio Médano Santa Clara, visitado en la década de 1970 por Guillermo Madrazo. La importancia de volver a estudiar este conjunto radica en que se trata de un sitio ubicado en el sector sudoccidental del Campo de Dunas del Centro Pampeano y a distancias variables de las principales fuentes de aprovisionamiento lítico. A partir de la información contextual y de las características del registro, se planteó que el sitio fue ocupado durante el Holoceno tardío y en el contacto Hispano-Indígena. Los nuevos datos indican una explotación mayoritaria de ftanita y ortocuarcita, procedentes de las Sierras de Tandilia, seguidas por rocas del monte xerófilo de la subregión Pampa Seca (chert y calcedonia) y Ventania (metacuarcita y riolita). Los modos de aprovisionamiento y los métodos y técnicas de talla empleados variaron con relación a las materias primas mayoritarias y minoritarias. Los resultados sugieren el aprovechamiento óptimo de las rocas, las cuales debieron ser trasladadas desde largas distancias. Por último, la representación de las rocas en el sitio contrasta con otros contextos del área indicando un uso diferencial de las materias primas hacia el sector oeste.
\end{abstract}

Palabras clave: Análisis tecnomorfológico; Estrategias de aprovisionamiento; Holoceno tardío; Pastizales pampeanos.

\begin{abstract}
The following article presents the technomorphological analysis of the Médano Santa Clara site lithic assemblage, visited for the first time by Guillermo Madrazo in 1970. The importance of re-studying this assemblage lies in the fact that is a site located in the southwestern sector of the Central Pampean Dunefields, at variable distances from the main raw material outcrops. Based on the contextual information and the characteristics of the record, it is suggested that the site was occupied in the late Holocene and during the Hispanic-Indigenous contact. The new data indicates a greater exploitation of chert and orthoquartzites from the Tandilia hills, followed by rocks from the xerophytic woodland of the Dry Pampas (silicified limestone and chalcedony) and Ventania hills (metaquartzite and rhyolite). Differences were observed in the procurement strategies and the methods and techniques employed between those majority and minority rocks. The results suggest the optimal use of the rocks, which should be transported from long distances. By last, the representation of the raw materials in the site contrast with other contexts from the study area, pointing out to a differential use of the rocks towards the western sector.
\end{abstract}

Keywords: Techno-morphological analysis; Procurement strategies; Late Holocene; Pampa grasslands.

Las investigaciones en el Campo de Dunas del Centro Pampeano (en adelante, CDCP) comenzaron a principios de la segunda mitad del Siglo XX con los trabajos pioneros de Bórmida $(1960,1962)$ y de Sanguinetti de Bórmida (1966), bajo los postulados teóricos y metodológicos de la Escuela Histórico-Cultural de Viena. Posteriormente, Madrazo (1973) formuló un nuevo modelo cronológico y cultural para las industrias pampeanas empleando algunos de los criterios clasificatorios de la Ecología Cultural norteamericana (Mazzanti, 2005). Para construir este modelo, este investigador utilizó los datos obtenidos del yacimiento Médano Santa Clara, el cual formaba parte del Aspecto de la Pampa Seca Oriental que se caracterizaba por la abundancia de piezas Bolivarenses (también denominado Complejo Calcedónico).

A casi cincuenta años de los trabajos realizados por Guillermo Madrazo en el Médano Santa Clara, se inició 
un proyecto denominado "Investigaciones arqueológicas en el Campo de Dunas del Centro Pampeano (partidos de Salliqueló y Pellegrini, provincia de Buenos Aires)", dirigido por uno de los autores (PGM). El objetivo principal de este proyecto es estudiar los procesos adaptativos y evolutivos de las sociedades cazadoras-recolectoras prehispánicas que ocuparon los diversos ambientes del centro-oeste de los pastizales pampeanos.

El CDCP constituye uno de los ambientes eólicos del centro de Argentina, el cual cubre la parte occidental y noroeste de la provincia de Buenos Aires, el este de La Pampa y el sur de Córdoba y Santa Fe (Figura 1). Geomorfológicamente, el área está formada por dunas lineales, de 100 a $130 \mathrm{~km}$ de largo y de 2 a $3 \mathrm{~km}$ de ancho, con una dirección general N-NE (Zárate y Tripaldi, 2012). En las depresiones de dichas dunas se registran numerosos cuerpos de agua poco profundos donde se localizan la mayoría de los sitios arqueológicos. Las cronologías de las ocupaciones en el CDCP corresponden a diferentes momentos del Holoceno (Messineo et al., 2018, 2019a; Oliva et al., 2015; Scheifler, 2019; Tapia et al., 2020, entre otros). Particularmente, el sitio Médano Santa Clara se localiza en el partido de Salliqueló, al oeste de la provincia de Buenos Aires, distando $10 \mathrm{~km}$ del límite con la provincia de La Pampa (Figura 1). La totalidad del partido de Salliqueló se encuentra dentro de la región Semiárida Bonaerense conformada por un ambiente semiárido, de suelos arenosos y con fuerte incidencia de la erosión eólica (Cabral et al., 2014).

En este contexto, en el presente trabajo se efectúa el análisis de la colección lítica generada por Madrazo del sitio Médano Santa Clara. El interés por volver a estudiar este conjunto radica en distintas razones. Por un lado, el informe presentado por este investigador se orientó principalmente a describir el conjunto cerámico y lítico recuperado, abarcando en este último caso sólo a los instrumentos tallados (Madrazo, 1972). Por lo tanto, los resultados generados por Madrazo son difíciles de utilizar en la actualidad, ya que para esa época no se determinaban de forma precisa las materias primas líticas, no se conocía la localización de las fuentes de aprovisionamiento en la región pampeana y no se analizaba el resto de las categorías artefactuales (núcleos y desechos), imposibilitando conocer las estrategias tecnológicas llevadas a cabo por los grupos humanos en el pasado. Por otro lado, este médano se ubica en el sector sudoccidental del CDCP y al oeste de otros sitios analizados para la provincia de Buenos Aires (e.g., Laguna Cabeza de Buey 2, Laguna Chica, Huencú Nazar y Laguna de los Pampas, entre otros), por lo cual resulta interesante para comprender cómo se desarrollaron las operaciones de talla en este sector.

En función de lo expuesto previamente, el principal objetivo de este trabajo es comprender las estrategias tecnológicas vinculadas con el aprovisionamiento, transporte y manufactura de los recursos líticos por parte de los grupos cazadores-recolectores que ocuparon el Médano Santa Clara. Si se considera que el CDCP no presenta afloramientos primarios ni secundarios de materias primas líticas (Figura 1; Messineo y Barros, 2021; Messineo et al., 2019b), resulta fundamental entender cómo se llevó a cabo la gestión de rocas en este sector del área de estudio y el transporte de las mismas desde diferentes puntos de la región pampeana. Para llevar a cabo estos objetivos, se determinarán las materias primas explotadas y las formas de obtención, los métodos de talla empleados sobre las rocas una vez en el sitio, los soportes buscados y las categorías artefactuales representadas en el conjunto. Por último, las tendencias tecnológicas identificadas en este yacimiento serán comparadas con aquellas obtenidas para otros sitios del CDCP, los cuales se localizan a distintas distancias de los principales afloramientos de rocas aptas para la confección de

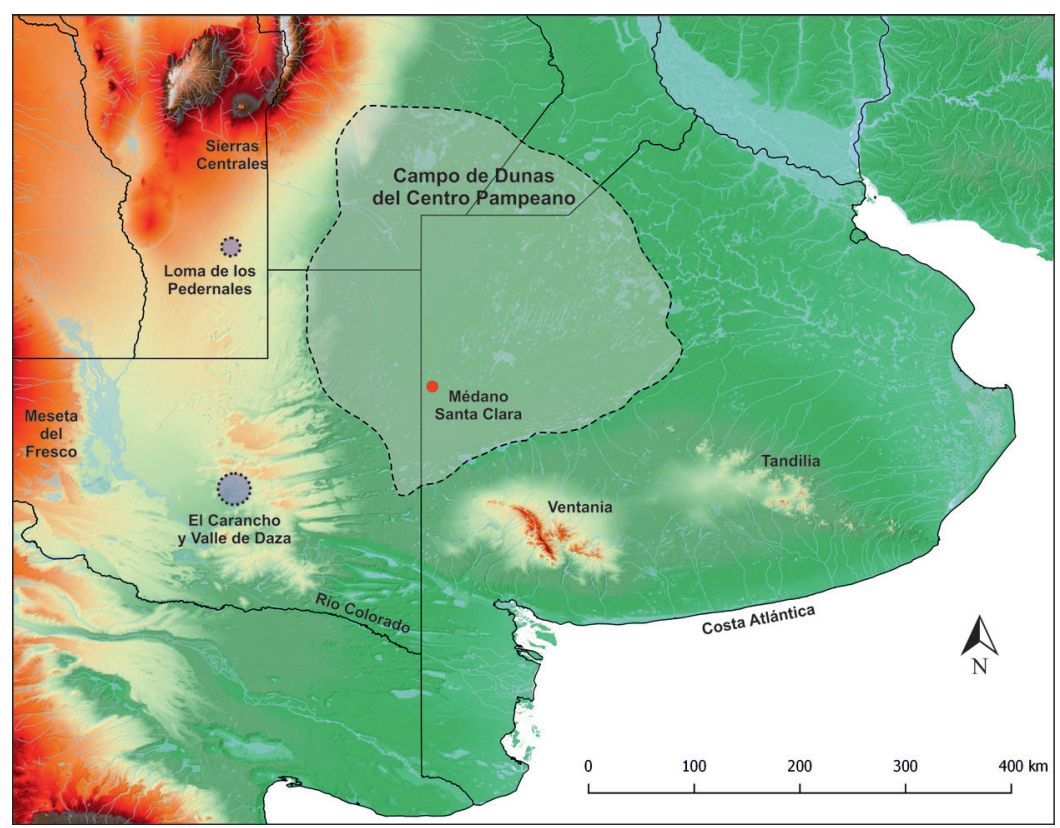

Figura 1. Ubicación del Médano Santa Clara en el Campo de Dunas del Centro Pampeano y de los principales afloramientos de rocas de la región pampeana y sectores adyacentes.

Figure 1. Location of the Médano Santa Clara site in the Central Pampean Dunefields and of the main rock outcrops of the pampean region and adjacent sectors. 
instrumentos.

\section{Investigaciones previas}

Como se mencionó en la introducción, los primeros datos sobre ocupaciones cazadoras-recolectoras en Salliqueló fueron generados por Guillermo Madrazo. Este investigador efectuó una única visita al sitio Médano Santa Clara en abril de 1971, mediante la invitación del señor Campomar Cervera, en ese entonces director del Museo de Historia Regional de Salliqueló. Según Madrazo (1972), el material recuperado durante su visita al yacimiento estaba compuesto por un conjunto sesgado como consecuencia de las constantes recolecciones de materiales que habían efectuado los aficionados a lo largo de varios años, particularmente de aquel material más atractivo. Hoy en día el material lítico tallado, recolectado previamente a la visita de Madrazo, se halla depositado en el museo, junto con piezas de molienda, boleadoras y un conjunto de siete instrumentos de cuarcita de grandes dimensiones. Sobre este último, el autor menciona que podría tratarse de un cache compuesto por cuatro raederas, dos bifaces y un núcleo (Madrazo, 1972: Fig. 13).

En cuanto a las tareas de recolección efectuadas por Madrazo, se destaca que el material fue obtenido de ocho microáreas contiguas dentro del médano, definidas como aquellos lugares de deflación con un piso de arena endurecido en donde se encontraba el material arqueológico (Madrazo, 1972). Si bien la mayoría de este material se recuperó en estas microáreas, menciona que algunas pocas piezas se ubicaban por encima de un suelo enterrado. Entre los principales hallazgos se destacan artefactos líticos, cerámica, elementos europeos (metales, botones y vidrio), restos óseos de guanaco y cáscara de huevo de rheidae.

Ante la falta de dataciones radiocarbónicas en la región pampeana para la época, Madrazo asignó cronológicamente al sitio en el Holoceno tardío y durante la conquista Hispano-Indígena, ya que en el conjunto recuperado se habían encontrado fragmentos de tiestos cerámicos (algunos decorados), puntas de flecha pequeñas e instrumentos confeccionados en vidrio. Asimismo, Madrazo (1972) planteó el predominio de la industria Bolivarense en el sitio, cuyo origen, según los postulados de Bórmida (1960, 1962), se remontaría a tiempos previos a la conquista Hispano-Indígena. Tanto Bórmida como Madrazo postularon que las puntas pequeñas y la cerámica se habrían introducido en la zona central de la Pampa Bonaerense por la difusión tardía (influencias neolíticas) de aquellas culturas procedentes de la región Andina-Subandina y Litoral, respectivamente (Bórmida, 1960; Madrazo, 1973).

\section{Materiales y métodos}

La muestra analizada comprende la totalidad de los materiales líticos ( $\mathrm{N}=654)$ recuperados por Madrazo en las ocho microáreas que conforman el Médano Santa Clara. Debido a que se trata de materiales superficiales procedentes de sectores contiguos dentro del mismo médano, se consideraron todos los artefactos como un único conjunto. No están incluidos en este análisis los materiales recuperados previamente por el Sr. Campomar Cervera, alojados en el Museo de Salliqueló, dado que se trata de artefactos de molienda recolectados en diferentes incursiones a los médanos de la zona (incluido Médano Santa Clara) a lo largo de diez años y cuya procedencia no es precisa.

En función de conocer aspectos como composición y estado de la muestra, materias primas empleadas y variedad de instrumentos, lascas y núcleos representados, se realizó un análisis tecnomorfológico siguiendo las propuestas de Andrefsky (1998), Aschero (1975, 1983), Aschero y Hocsman (2004), Bellelli y colaboradores (1985-1987) y Santos Valero (2017), entre otros. Para la clasificación de las rocas se efectuó una aproximación macroscópica, utilizando muestras de mano de la litoteca del INCUAPA-CONICET y determinaciones obtenidas de trabajos publicados para la región pampeana y sectores aledaños (Bayón et al., 1999; Berón, 2006; Bonomo y Prates, 2014; Carrera Aizpitarte, 2014; Carrera Aizpitarte et al., 2015; Catella et al., 2013; Heider, 2015; Heider y Demichelis, 2015; Messineo y Barros, 2015; Santos Valero, 2017, entre otros). Se analizaron variables como materias primas representadas, estado de la muestra, dimensiones relativas (tamaños y módulos), grupos tipológicos de los instrumentos, tipos de núcleos y dirección de los lascados, tipos de lascas y talones (para estas dos últimas variables sólo se consideraron las enteras y fracturadas con talón; $\mathrm{n}=256$ ), entre otras. También se evaluó la presencia de remanente de corteza en la totalidad del material. Los resultados serán presentados siguiendo como eje las materias primas identificadas, en función de entender cómo se llevaron a cabo las operaciones de talla.

\section{Resultados}

La muestra analizada se compone principalmente de lascas $(60,9 \%)$ e instrumentos $(36,5 \%)$, mientras que en frecuencias muy bajas se registraron núcleos y desechos indeterminables (Tabla 1). Respecto de las materias primas, la ftanita es la roca mejor representada $(33,2 \%)$, seguida por la ortocuarcita $(28,4 \%)$ y el chert $(18,7 \%)$, mientras que en menores proporciones se registra la metacuarcita, la calcedonia ${ }^{1}$ y la riolita, entre otras (Tabla 1). Con relación al estado de la colección, el $69 \%$ de los artefactos se encuentra fracturado, lo cual podría deberse al carácter superficial de la muestra y

\footnotetext{
1 En este trabajo el término calcedonia hace referencia a un tipo de roca de color blanquecino y corteza blanca, distinguible claramente a nivel macroscópico tanto del chert como de la ftanita. Se prevé realizar cortes delgados sobre la calcedonia para identificar el lugar preciso de procedencia de esta roca.
} 


\begin{tabular}{|c|c|c|c|c|c|c|}
\hline \multirow{2}{*}{ Materia prima } & \multicolumn{6}{|c|}{ Categoría artefactual } \\
\hline & Lasca & Instrumento & Núcleo & Des. Ind. & Total & $\%$ \\
\hline Ftanita & 124 & 85 & 6 & 2 & 217 & 33,2 \\
\hline Ortocuarcita & 115 & 68 & 3 & - & 186 & 28,4 \\
\hline Chert & 74 & 48 & - & - & 122 & 18,7 \\
\hline Metacuarcita & 30 & 6 & 1 & - & 37 & 5,7 \\
\hline Calcedonia & 16 & 15 & - & - & 31 & 4,7 \\
\hline Riolita & 14 & 7 & - & - & 21 & 3,2 \\
\hline Dolomía silicificada & 10 & 2 & - & - & 12 & 1,8 \\
\hline Indeterminables & 8 & 3 & - & 1 & 12 & 1,8 \\
\hline Arenisca cuarzosa & 3 & 3 & - & 2 & 8 & 1,2 \\
\hline Rocas silíceas & 4 & 1 & - & - & 5 & 0,8 \\
\hline Xilópalo & - & 1 & - & - & 1 & 0,2 \\
\hline Cuarzo & - & - & 1 & - & 1 & 0,2 \\
\hline Basalto/andesita & - & - & - & 1 & 1 & 0,2 \\
\hline Total & 398 & 239 & 11 & 6 & 654 & 100 \\
\hline$\%$ & 60,9 & 36,5 & 1,7 & 0,9 & 100 & \\
\hline
\end{tabular}

Tabla 1. Categorías artefactuales y materias primas representadas en el conjunto lítico del sitio Médano Santa Clara.

Referencias: Des. Ind.: Desechos indeterminables.

Table 1. Artefactual categories and raw materials represented in the Médano Santa Clara lithic assemblage.

References: Des. Ind.: Debris a la dinámica geomorfológica del médano (Madrazo, 1972). En el 32,3\% de las piezas se registró la presencia de aristas pulidas como producto de su exposición a las condiciones atmosféricas, donde predominó la erosión eólica. Por último, el 1,5\% del conjunto posee evidencias de alteración térmica, correspondiéndose a desechos e instrumentos de chert $(n=4)$, ortocuarcita, ftanita $(n=2$, en cada caso), dolomía silicificada y riolita ( $n=1$, en cada caso).

\section{Ftanita}

El conjunto de artefactos de ftanita se encuentra comprendido mayoritariamente por lascas (Tabla 1), sobresaliendo entre ellas las angulares $(37,3 \%)$ e indeterminables (36,1\%; Tabla 2). Se trata de desechos de talla pequeños $(51,8 \%)$ y espesos $(44,6 \%$; Tabla 3$)$. Con respecto a los talones $(n=83)$ predominan los filiformes $(44,6 \%)$ y los lisos $(27,7 \%)$. Con una menor representación se registraron también facetados, puntiformes $(8,4 \%$, en cada caso), diedros (6\%), lisos naturales $(3,6 \%)$ y uno natural cortical (1,2\%). En líneas generales, el 79,5\% del total de los desechos no presentan corteza en su cara dorsal, mientras que en un $14,5 \%$ no cubre el $50 \%$ de la misma. En menor medida están representados aquellos desechos que poseen más del $50 \%$ de reservas de corteza $(3,6 \%)$ y aquellos donde toda su cara dorsal está cubierta $(2,4 \%)$.

Con respecto a los instrumentos, se registraron 12 grupos tipológicos (Tabla 4), donde sobresalen los instrumentos compuestos, los raspadores (Figura 2f) y los filos en bisel asimétrico unifacial (Figura 2c). Entre los primeros, predominan a su vez, aquellos representados por frentes de raspador $(73,2 \%)$ y filos en bisel asimétrico unifacial (46,3\%). Son instrumentos mayoritariamente pequeños $(43,5 \%)$ y espesos (29,4\%; Tabla 3), desarrollados sobre lascas $(91,8 \%)$, entre las que se encuentran las indeterminables $(66,7 \%)$, las angulares $(20,5 \%)$, de arista $(10,3 \%)$, de dorso natural y primarias $(1,3 \%$, en cada caso). La mayoría de los filos fueron delineados por

Tabla 2. Frecuencias de los tipos de lascas enteras y fracturadas con talón representados en aquellas rocas con más de 10 desechos.

Table 2: Frequencies of whole and fractured with platform flake types represented among those rocks with more than 10 flakes.

\begin{tabular}{|c|c|c|c|c|c|c|}
\hline Tipo de lasca & $\begin{array}{c}\text { Ftanita } \\
(\mathbf{n}=\mathbf{8 3})\end{array}$ & $\begin{array}{c}\text { Ortocuarcita } \\
(\mathrm{n}=\mathbf{7 8})\end{array}$ & $\begin{array}{c}\text { Chert } \\
(\mathrm{n}=\mathbf{3 6})\end{array}$ & $\begin{array}{c}\text { Metacuarcita } \\
(\mathbf{n}=\mathbf{2 4})\end{array}$ & $\begin{array}{c}\text { Calcedonia } \\
(\mathbf{n}=\mathbf{1 1})\end{array}$ & $\begin{array}{c}\text { Riolita } \\
(\mathbf{n}=\mathbf{1 0})\end{array}$ \\
\hline Angular & 37,3 & 47,4 & 50 & 37,5 & 54,5 & 50 \\
\hline Indeterminable & 36,1 & 32,1 & 30,6 & 37,5 & 36,4 & 40 \\
\hline De arista & 18,1 & 14,1 & 8,3 & 8,3 & - & - \\
\hline Secundaria & 4,8 & 1,3 & - & 4,2 & 9,1 & - \\
\hline Primaria & 2,4 & 1,3 & 2,8 & 8,3 & - & - \\
\hline Dorso natural & 1,2 & - & 2,8 & - & - & 10 \\
\hline Plana & - & 2,6 & 2,8 & 4,2 & - & - \\
\hline
\end{tabular}




\begin{tabular}{|c|c|c|c|c|c|c|c|c|c|c|c|c|c|c|c|}
\hline & \multicolumn{3}{|c|}{ Ftanita } & \multicolumn{3}{|c|}{ Ortocuarcita } & \multicolumn{2}{|c|}{ Chert } & \multicolumn{3}{|c|}{ Metacuarcita } & \multicolumn{2}{|c|}{ Calcedonia } & \multicolumn{2}{|c|}{ Riolita } \\
\hline & $\begin{array}{c}\mathrm{L} \\
\mathrm{n}=(124)\end{array}$ & $\begin{array}{c}\mathrm{I} \\
\mathrm{n}=(85)\end{array}$ & $\begin{array}{c}N \\
n=(6)\end{array}$ & $\begin{array}{c}\mathrm{L} \\
\mathrm{n}=(115)\end{array}$ & $\begin{array}{c}\mathrm{I} \\
\mathrm{n}=(68)\end{array}$ & $\begin{array}{c}\mathrm{N} \\
\mathrm{n}=(3)\end{array}$ & $\begin{array}{c}\mathrm{L} \\
\mathrm{n}=(74)\end{array}$ & $\begin{array}{c}\mathrm{I} \\
\mathrm{n}=(48)\end{array}$ & $\begin{array}{c}\mathrm{L} \\
\mathrm{n}=(30)\end{array}$ & $\begin{array}{c}1 \\
n=(6)\end{array}$ & $\begin{array}{c}N \\
n=(1)\end{array}$ & $\begin{array}{c}\mathrm{L} \\
\mathrm{n}=(16)\end{array}$ & $\begin{array}{c}\mathbf{I} \\
\mathrm{n}=(15)\end{array}$ & $\begin{array}{c}\mathrm{L} \\
\mathrm{n}=(14)\end{array}$ & $\begin{array}{c}\mathrm{I} \\
\mathrm{n}=(7)\end{array}$ \\
\hline \multicolumn{16}{|c|}{ Tamaños } \\
\hline Pequeño & 51,8 & 43,5 & - & 37,2 & 17,6 & 33,3 & 44,4 & 31,3 & 29,2 & - & - & 63,6 & 40 & 30 & - \\
\hline Mediano pequeño & 32,5 & 16,5 & 50 & 33,3 & 23,5 & 33,3 & 44,4 & 27,1 & 25 & - & - & 27,3 & 6,7 & 30 & 14,3 \\
\hline Mediano grande & 1,2 & 2,4 & 50 & 5,1 & 22,1 & 33,3 & - & - & 25 & - & 100 & - & - & 10 & 28,6 \\
\hline Grande & 1,2 & 1,2 & - & 1,3 & 5,9 & - & - & - & 12,5 & 66,7 & - & - & - & - & 42,9 \\
\hline Muy grande & - & - & - & - & - & - & - & - & - & - & - & - & - & - & 14,3 \\
\hline No ident. por fr. & 13,3 & 36,5 & - & 23,1 & 30,9 & - & 11,1 & 41,7 & 8,3 & 33,3 & - & 9,1 & 53,3 & 30 & - \\
\hline \multicolumn{16}{|c|}{ Módulo A/E } \\
\hline Muy espeso & 7,2 & 27,1 & 100 & 12,8 & 27,9 & 100 & 11,1 & 25,0 & 29,2 & - & 100 & 9,1 & 13,3 & 10 & - \\
\hline Espeso & 44,6 & 29,4 & - & 33,3 & 38,2 & - & 27,8 & 29,2 & 29,2 & 66,7 & - & 54,5 & 33,3 & 30 & 57,1 \\
\hline Poco espeso & 34,9 & 7,1 & - & 30,8 & 2,9 & - & 50,0 & 4,2 & 33,3 & - & - & 27,3 & - & 30 & - \\
\hline No ident. por fr. & 13,3 & 36,5 & - & 23,1 & 30,9 & - & 11,1 & 41,7 & 8,3 & 33,3 & - & 9,1 & 53,3 & 30 & 42,9 \\
\hline
\end{tabular}

Tabla 3. Tamaños y espesores de las lascas, instrumentos y núcleos de aquellas rocas con más del $2 \%$ de representación.

Referencias: L: Lasca; I: Instrumento; N: Núcleo; No ident. por fr.: No identificado por fractura; Módulo A/E: Módulo de Ancho/Espesor.

Table 3. Sizes and thicknesses of the flakes, tools and cores of those rocks with more than 2\% of representation in the assemblage.

References: L: Flake; I: Tool; N: Core; No ident. por fr.: Unidentified; Módulo A/E: Width/Thickness Module.

microretoques marginales $(45,1 \%)$ y retoques marginales (33,5\%). En menor medida, se registró el empleo de retoques más microretoques marginales $(13,4 \%)$, retoques extendidos $(7,3 \%)$ y machacado $(0,6 \%)$.

Los seis núcleos de ftanita (Figura $2 \mathrm{~m}$ ) fueron desarrollados sobre soportes indeterminables (50\%), nódulos (33,3\%) y lascas $(16,7 \%)$. Son artefactos mediano grandes, mediano pequeños (50\%, en cada caso) y muy espesos (100\%; Tabla 3). Tipológicamente, pueden clasificarse como núcleos bipolares, piramidales regulares (33,3\%, en cada caso), globulosos y poliédricos (16,7\%, en casa caso). La mitad de los núcleos presenta lascados multidireccionales $(50 \%) y$, en menor medida, se registraron con lascados bidireccionales $(33,3 \%)$ y unidireccionales $(16,7 \%)$. A excepción de dos casos, el resto de los núcleos se recuperaron agotados (Figura $2 \mathrm{~m}$ ).

Figura 2. Instrumentos y núcleos del Médano Santa Clara. Referencias: a) Instrumento compuesto sobre riolita; b) Instrumento compuesto sobre ortocuarcita; c) Filo en bisel asimétrico unifacial sobre ftanita; d) Raedera doble convergente sobre ortocuarcita; e) Raspadores sobre chert; f) Raspadores sobre ftanita; g) Piéces esquillées sobre ortocuarcita; h) Piéce esquillée sobre chert; i) Punta de proyectil de xilópalo; j) Punta de proyectil de ftanita; k) Puntas de proyectil de ortocuarcita; I) Puntas de proyectil de chert; $m$ ) Núcleos de ftanita; $n$ ) Núcleos de ortocuarcita; o) Núcleo de metacuarcita; p) Núcleo de cuarzo.

Figure 2. Tools and cores from Médano Santa Clara site. References: a) Composed tool on rhyolite; b) Composed tool on orthoquartzite; c) Unifacial edged tool on chert; d) Doble convergent side scraper tool on orthoquartzite; e) Endscrapers on silicified limestone; f) Endscrapers on chert; g) Piéces esquillées on orthoquartzite; h) Piéces esquillées on silicified limestone; i) Projectile point on silicified wood; j) Projectile point on chert; k) Projectile points on orthoquartzite; I) Projectile points on silicified limestone; $m$ ) Chert cores; $n$ ) Orthoquartzite cores; o) Metaquartzite core; p) Quartz core.

\section{Ortocuarcita}

El conjunto de artefactos de ortocuarcita está compuesto en su mayoría por lascas (Tabla 1), entre las que sobresalen las angulares $(47,4 \%)$ e indeterminables $(32,1 \%$; Tabla 2$)$. Predominan los desechos pequeños $(37,2 \%)$ y espesos (33,3\%; Tabla 3). Los talones $(n=78)$ mejor representados son los filiformes $(52,6 \%)$ y lisos $(29,5 \%)$. Les siguen en frecuencia los diedros (9\%), puntiformes $(5,1 \%)$, facetados $(2,6 \%)$ y uno liso natural $(1,3 \%)$. El $92,3 \%$ de las lascas no presenta corteza en su cara dorsal. En frecuencias menores están representadas aquellas donde

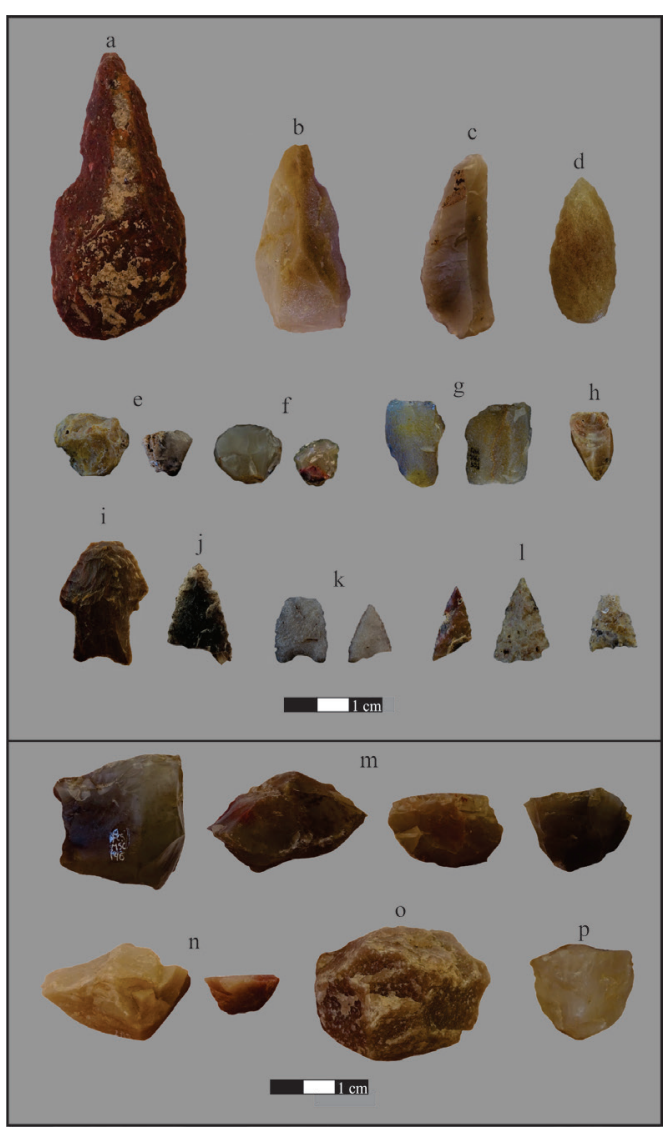




\begin{tabular}{|c|c|c|c|c|c|c|c|c|c|c|c|c|c|}
\hline $\begin{array}{c}\text { Materia prima/ } \\
\text { Grupo tipológico }\end{array}$ & Ftanita & Ortocuar. & Chert & Calcedonia & Riolita & Metacuarc. & Arenisca c. & Indeterm. & Dolomía & Silice & Xilópalo & Total & $\%$ \\
\hline Inst. compuesto & 39 & 29 & 14 & 6 & 4 & 2 & - & - & 2 & - & - & 96 & 40,2 \\
\hline Raspador & 23 & 7 & 8 & 8 & - & 1 & - & - & - & - & - & 47 & 19,7 \\
\hline Fbau. & 7 & 13 & 7 & 1 & - & - & - & - & - & - & - & 28 & 12 \\
\hline Punta proyectil & 1 & 4 & 8 & - & - & 1 & - & - & - & - & 1 & 15 & 6,3 \\
\hline Lasca r.c. & 5 & 6 & 4 & - & 1 & 1 & - & 2 & - & - & - & 19 & 7,9 \\
\hline Filo bifacial & 1 & - & 1 & - & 1 & - & - & - & - & - & - & 3 & 1 \\
\hline Raedera & 1 & 4 & - & - & - & - & - & - & - & - & - & 5 & 2,1 \\
\hline Piéce esquillée & 1 & 2 & 1 & - & - & - & - & - & - & - & - & 4 & 1,7 \\
\hline Raclette & 3 & 1 & - & - & - & - & - & - & - & - & - & 4 & 1,7 \\
\hline Inst. bifacial & 2 & - & 1 & - & - & - & - & - & - & - & - & 3 & 1,3 \\
\hline Inst. indeterm. & - & - & 2 & - & - & - & - & - & - & 1 & - & 3 & 1,3 \\
\hline Lasca r.s. & 1 & 1 & - & - & 1 & - & - & - & - & - & - & 3 & 1,3 \\
\hline Muesca & 1 & 1 & 1 & - & - & - & - & - & - & - & - & 3 & 1,3 \\
\hline Molienda & - & - & - & - & - & - & 3 & - & - & - & - & 3 & 1,3 \\
\hline Bola & - & - & - & - & - & - & - & 1 & - & - & - & 1 & 0,4 \\
\hline Cuchillo & - & - & - & - & - & 1 & - & - & - & - & - & 1 & 0,4 \\
\hline Preforma bifaz & - & - & 1 & - & - & - & - & - & - & - & - & 1 & 0,4 \\
\hline Total & 85 & 68 & 48 & 15 & 7 & 6 & 3 & 3 & 2 & 1 & 1 & 239 & 100 \\
\hline$\%$ & 35,6 & 28,5 & 20,1 & 6,3 & 3 & 2,5 & 1,3 & 1,3 & 0,8 & 0,4 & 0,4 & 100 & \\
\hline
\end{tabular}

Tabla 4. Grupos tipológicos representados en los instrumentos analizados.

Referencias: Inst.: Instrumento; Fbau: Filo en bisel asimétrico unifacial; Lasca r.c.: Lasca rastros complementarios; Lasca r.s.: Lasca retoque sumario; Ortocuarc.: Ortocuarcita; Metacuarc.: Metacuarcita; Arenisca c.: Arenisca cuarzosa; Indeterm.: Indeterminable.

Table 4. Typological groups represented among the analyzed tools.

References: Inst.: Tool; Fbau: Unifacial edged tool; Lasca r.c.: Flake with complementary traces; Lasca r.s.: Flake with summary edge-retouch; Ortocuarc.: Orthoquartzite; Metacuarc.: Metaquartzite; Arenisca c.: Quartz Sandstone; Indeterm.: Undeterminable.

la corteza no cubre el $50 \%$ de la cara dorsal $(5,1 \%)$ y los desechos que poseen corteza en más del $50 \%$ de su cara dorsal $(2,6 \%)$.

Dentro del grupo de los instrumentos, se registraron 10 grupos tipológicos (Tabla 4), entre los que se destacan los instrumentos compuestos (Figura 2b), los filos en bisel asimétrico unifacial, los raspadores, las raederas (Figura $2 \mathrm{~d}$ ) y las puntas de proyectil (Figura 2k). Los instrumentos compuestos se caracterizan por la alta frecuencia de filos en bisel asimétrico unifacial $(77,4 \%)$ y muescas $(41,9 \%)$. Se trata de instrumentos mayoritariamente mediano pequeños (23,5\%) y espesos (38,2\%; Tabla 3). Entre los soportes identificados, se registraron distintos tipos de lascas $(89,7 \%)$ y un nódulo. Con respecto a las primeras, se registraron lascas indeterminables $(73,8 \%)$, angulares $(18 \%)$, de arista, primarias $(3,3 \%$, en cada caso) y de dorso natural (1,6\%). La delineación de los filos se realizó, en la mayoría de los casos, mediante retoques marginales (38,9\%) y microretoques marginales $(29,4 \%)$. Otras series técnicas identificadas fueron el retoque y microretoque marginal $(23,8 \%)$, el retoque parcialmente extendido $(5,6 \%)$, el retoque extendido $(1,6 \%)$ y la talla parcialmente extendida con retoque marginal $(0,8 \%)$.

En ninguno de los tres núcleos pudieron identificarse los soportes empleados. Con respecto a los tamaños, pertenecen a las categorías pequeña, mediana pequeña y mediana grande. En todos los casos son artefactos muy espesos (Tabla 3). Dos de los núcleos presentan lascados multidireccionales, mientras que el restante negativos unidireccionales. En todos los casos, se trata de núcleos piramidales regulares (Figura 2n) y dos de ellos se recuperaron agotados.

\section{Chert}

Dentro del conjunto de los cherts, las lascas son la categoría artefactual mejor representada (Tabla 1). Tipológicamente predominan aquellas angulares (50\%) e indeterminables (30,6\%; Tabla 2). Se trata de artefactos pequeños y mediano pequeños $(44,4 \%$, en cada caso) y poco espesos (50\%; Tabla 3). Entre los talones $(n=36)$ presentes se destacan los filiformes $(47,2 \%)$ y lisos $(19,4 \%)$. En menor medida, se identificaron talones facetados $(13,9 \%)$, puntiformes, diedros $(8,3 \%$, en cada caso) y uno liso natural $(2,8 \%)$. El $80,6 \%$ de la muestra no presenta corteza en su cara dorsal, mientras que en el $13,9 \%$ la corteza no sobrepasa el $50 \%$ de la cara dorsal. En mucha menor frecuencia, se encuentran aquellos desechos con más del $50 \%$ de su cara dorsal cubierta de corteza y con la totalidad de su cara dorsal con corteza ( $2,8 \%$, en cada caso).

Con respecto a los instrumentos, se registraron 10 grupos tipológicos (Tabla 4), sobresaliendo los instrumentos compuestos, las puntas de proyectil (Figura 2I) y los raspadores (Figura 2e). Dentro del primer grupo predominan aquellos con filos de raspador (12\%) y filos en bisel asimétrico unifacial $(11,1 \%)$. Se destaca la presencia de ocho puntas de proyectil, las cuales son triangulares apedunculadas (Figura 2l). Con relación a las dimensiones relativas, los instrumentos pequeños 
(31,3\%) y espesos son los más frecuentes (29,2\%; Tabla 3). Para la confección de los instrumentos se emplearon mayoritariamente lascas $(79,2 \%)$, soportes indeterminables $(16,7 \%)$ y dos plaquetas $(4,2 \%)$. Entre las primeras, se registraron lascas indeterminables $(68,4 \%)$, angulares $(18,4 \%)$, primarias $(7,9 \%)$, de arista y secundarias $(2,6 \%$, en cada caso). La delineación de los filos se llevó a cabo, mayoritariamente, a partir de microretoques marginales $(47,4 \%)$. En menor medida, se registró el empleo de retoques marginales $(17,5 \%)$, retoques extendidos $(11,3 \%)$, retoques más microretoques marginales $(12,4 \%)$, retoques parcialmente extendidos $(6,2 \%)$ y microretoques extendidos $(5,2 \%)$.

\section{Otras rocas}

Entre aquellas rocas que no superan el $10 \%$ de la muestra, la más frecuente es la metacuarcita (5,7\%; Tabla 1). Esta materia prima se encuentra representada mayoritariamente por lascas, entre las que sobresalen las angulares e indeterminables (37,5\%, en cada caso; Tabla 2). Son artefactos predominantemente pequeños (29,2\%) y poco espesos (33,3\%; Tabla 3). Con respecto a los talones $(n=24)$, se observa cierta variabilidad, donde los filiformes son los más numerosos (50\%). Le siguen en frecuencia los lisos (33,3\%), naturales corticales (8,3\%), liso natural y diedro (4,2\%, en cada caso). El $83,4 \%$ de este conjunto no presenta remanentes de corteza, seguidos en frecuencia por aquellos donde la corteza sobrepasa el $50 \%$ de la cara dorsal o donde la cubre completamente (8,3\%, en cada caso).

En relación con los instrumentos, se identificaron dos compuestos, un raspador, una punta de proyectil y un cuchillo (Tabla 4). Se trata en todos los casos de artefactos espesos y grandes $(66,7 \%$, en cada caso; Tabla 3). Los soportes empleados fueron lascas $(66,7 \%)$ y desechos indeterminables (33,3\%). Entre las primeras, se identificaron dos angulares, una primaria y una indeterminable. Para delinear los filos se emplearon en la mayoría de los casos retoques marginales (60\%) y, en menor medida, retoques extendidos y talla marginal (20\%, en cada caso). El único núcleo de metacuarcita es grande y muy espeso (Tabla 3; Figura 20), desarrollado sobre un soporte no identificable. Es de morfología globulosa, no se encuentra agotado y presenta lascados multidireccionales.

El conjunto de calcedonias (4,7\%) está comprendido casi equitativamente por lascas e instrumentos (Tabla 1). Entre las primeras sólo se encuentran representadas las angulares $(54,5 \%)$, indeterminables $(36,4 \%)$ y secundarias $(9,1 \%$; Tabla 2$)$. Con respecto a los talones $(n=11)$, se encuentran representados los filiformes $(54,5 \%)$, lisos $(27,3 \%)$ y puntiformes $(18,2 \%)$. Tanto en esta roca como en el resto de las minoritarias, las lascas pequeñas $(63,3 \%)$ y espesas $(54,5 \%)$ son las mejor representadas (Tabla 3). Casi la totalidad de las lascas carece de corteza
$(81,8 \%)$, con dos ejemplares que presentan corteza en menos del $50 \%$ de su cara dorsal y otro donde la corteza sobrepasa el $50 \%$ de esta misma cara $(9,1 \%$ en cada caso). En relación con los instrumentos de calcedonia, se registraron raspadores, instrumentos compuestos y un filo en bisel asimétrico unifacial (Tabla 4). En todos los casos, los soportes elegidos fueron lascas, donde las indeterminables son las más frecuentes $(66,7 \%)$, seguidas de las secundarias (20\%), angulares y de arista (6,7\%, en cada caso). Se trata de instrumentos mayoritariamente pequeños (40\%) y espesos (33,3\%; Tabla 3). Los soportes fueron trabajados por medio de microretoques marginales (30\%), retoques marginales y microretoques extendidos (20\%, en cada caso). En menor medida, se registraron filos delineados por medio de retoques extendidos (13,3\%), retoques extendidos más microretoques marginales (10\%) y retoques más microretoques marginales $(6,7 \%)$.

Con respecto a las riolitas $(3,2 \%)$, se identificó la presencia de lascas e instrumentos (Tabla 1). Entre las primeras sólo se encuentran representadas las angulares (50\%), indeterminadas (40\%) y planas (10\%; Tabla 2). Con respecto a los talones $(n=10)$, sólo se encuentran presentes los lisos (70\%) y filiformes (30\%). A excepción de una lasca que presenta corteza en menos de la mitad de su cara dorsal, el resto de los desechos no posee (92,9\%). Con respecto a los instrumentos, predominan los compuestos (Figura 2a; Tabla 4). Los soportes empleados fueron lascas indeterminables $(71,4 \%)$ y angulares $(28,6 \%)$. Son artefactos de tamaños generalmente grandes (42,9\%) y espesos (57,1\%; Tabla 3). En la mayoría de los casos, los filos se delinearon por medio de retoques marginales $(46,7 \%)$, con un menor empleo de retoque más microretoque marginal $(26,7 \%)$, microretoque marginal $(13,3 \%)$, talla extendida y machacado $(6,7 \%$, en cada caso).

Las dolomías silicificadas (1,8\%) se encuentran representadas por diez lascas y dos instrumentos (Tabla 1). Entre las primeras, considerando aquellas que presentan talón $(n=9)$, las angulares son las más frecuentes $(66,7 \%)$, seguidas en proporción por las indeterminables $(22,2 \%)$ y dorso natural $(11,1 \%)$. Son artefactos mayoritariamente pequeños (44,4\%) y espesos (33,3\%). En menor medida, se registraron piezas mediano pequeñas (33,3\%), poco espesas y espesas (22,2\%, en cada caso). Entre los talones predominan los filiformes $(55,6 \%)$. Con un ejemplar cada uno, se identificaron también talones del tipo liso, liso natural, puntiforme y diedro. Casi la totalidad de las lascas $(77,8 \%)$ no presenta corteza en su cara dorsal. Solo se registró un ejemplar donde la corteza no sobrepasa el $50 \%$ de la cara dorsal y otro donde la corteza abarca más de la mitad. Los dos instrumentos son compuestos desarrollados sobre una lasca indeterminable y otra angular. Mientras que uno de ellos es pequeño y muy espeso, en el otro la presencia de fracturas impidió establecer las dimensiones relativas. En ambos casos, se empleó el microretoque marginal para la realización de 
los filos.

La arenisca cuarzosa $(1,2 \%)$ se encuentra representada bajo la forma de tres lascas y tres fragmentos de instrumentos (Tabla 1). Las primeras son, en todos los casos, indeterminables, mediano pequeñas y espesas. Entre los talones están representados dos filiformes y uno liso. Ninguna de las lascas presenta corteza en la cara dorsal. Con respecto a los instrumentos, se trata en todos los casos de fragmentos de instrumentos modificados por medio de picado, abrasión y pulido, realizados sobre plaquetas. En un solo caso pudo identificarse la presencia de un borde correspondiente a una superficie pasiva de molienda.

El conjunto de las rocas silíceas $(0,8 \%)$ está comprendido por cuatro lascas y un instrumento (Tabla 1). En cuanto a este último, es indeterminable y confeccionado sobre una lasca. Debido a la presencia de fracturas, no fue posible establecer las categorías de tamaño y espesor. Presenta retoques marginales bifaciales en un sector restringido. Con respecto a las lascas, entre aquellas que poseían talón, se identificaron una indeterminable y una angular. La primera es de tamaño mediano pequeño y muy espesa, mientras que la segunda es pequeña y espesa. Entre los talones se registró uno filiforme y uno facetado. Ninguna lasca posee remanentes de corteza en su cara dorsal.

El xilópalo, el cuarzo y el basalto/andesita están representados por un artefacto cada una (0,2\%; Tabla 1). La primera de estas rocas está presente como una punta de proyectil pedunculada (Figura $2 \mathrm{i}$ ), de tamaño mediano grande y muy espesa. La confección de este instrumento implicó el retoque extendido bifacial de un soporte que no pudo ser identificado. El cuarzo corresponde a un núcleo mediano pequeño y muy espeso. Es de morfología globulosa, con negativos de lascados multidireccionales (Figura 2p) y se encuentra agotado. En basalto/andesita se recuperó un desecho indeterminable con sus aristas completamente pulidas. Finalmente, entre las rocas indeterminables se identificó una bola de boleadora, dos lascas con retoques complementarios (Tabla 4) y ocho desechos de talla (Tabla 1).

\section{Discusiones}

\section{Procedencia de las materias primas}

El análisis tecnomorfológico del sitio Médano Santa Clara permitió establecer cómo fue el empleo de materias primas procedentes de diferentes áreas de la región pampeana (Tabla 1). En este sentido, las dos principales rocas explotadas son la ftanita de la Formación Cerro Largo (Barros et al., 2015; Messineo y Barros, 2015) y la ortocuarcita del Grupo Sierras Bayas (Barros et al., 2021; Bayón et al., 1999; Colombo, 2011; Messineo, 2008, entre otros). Ambas materias primas afloran en el sector noroccidental y centro-este de las Sierras de Tandilia (entre 200 y 350 km al este-sudeste del sitio; Figura 1). Otra roca cuya fuente se localiza en este cordón serrano es la dolomía silicificada (Messineo y Barros, 2015), presente en frecuencias mucho menores (Tabla 1).

Siguiendo el orden de representación de las rocas en el conjunto analizado, se registró el chert, cuyo origen posiblemente se encuentre en el monte xerófilo de la subregión Pampa Seca. Si bien a nivel macroscópico estas rocas muestran grandes similitudes con las registradas en diferentes sitios y canteras de la provincia de La Pampa, como Meseta del Fresco (ca. $400 \mathrm{~km}$ al sudoeste del sitio), Laguna El Carancho (ca. 200 km del sitio) y el Valle de Daza (ca. 170 km del sitio; Figura 1; Berón, 2006; Carrera Aizpitarte, 2014; Charlin, 2002), serán necesarios cortes delgados para poder establecer cuáles son las fuentes puntuales de procedencia que emplearon los grupos que ocuparon el sitio.

Otra fuente de aprovisionamiento de rocas la constituyeron las Sierras de Ventania (ca. $130 \mathrm{~km}$ al sur del sitio; Figura 1), de las cuales los cazadores-recolectores se habrían aprovisionado de metacuarcitas, riolitas y areniscas cuarzosas (Bayón et al., 1999; Catella, 2014; Catella et al., 2010; Martínez y Santos Valero, 2020). Con respecto a la calcedonia, pudieron constatarse similitudes macroscópicas con aquellas identificadas por Heider (2015) y Heider y Demichelis (2015) en la cantera de Loma de los Pedernales (ca. $300 \mathrm{~km}$ al noroeste del sitio), localizada en el centro-sur de la provincia de San Luis (Figura 1). Sin embargo, al igual que en el caso del chert, se deberán realizar cortes delgados para establecer la fuente de manera fehaciente. Finalmente, se cuenta con rocas de uso minoritario, como sílices, xilópalo, cuarzo y basalto/andesita. En todos los casos se trata de materias primas que pueden obtenerse bajo la forma de rodados en la costa Atlántica (ca. $560 \mathrm{~km}$ al sudeste del sitio; Figura 1; Bonomo y Prates, 2014) y/o el Manto Tehuelche que se extiende de manera discontinua desde el río Colorado hacia el norte, incluyendo también el sur de la provincia de La Pampa y Buenos Aires (ca. 300 km al sur del sitio; Martínez et al., 2009).

A nivel areal se pueden observar algunas diferencias en las frecuencias de las rocas representadas cuando se comparan los valores de Médano Santa Clara con otros contextos del CDCP (Berón et al., 2015; Gavilán et al., 2004; Heider, 2015; Messineo et al., 2018, 2019b, 2019c, Oliva et al., 2004; Scheifler et al., 2017). Las rocas de Tandilia poseen un valor de $63,4 \%$, mientras que en la mayoría de los sitios que se localizan hacia el oriente del Médano Santa Clara las frecuencias son superiores al $90 \%$, estando el resto de las rocas representadas en muy bajos porcentajes (Figura 3).

Otra diferencia destacable es la alta representación del chert (18\%) en Médano Santa Clara, ya que esta roca se halla en muy bajas frecuencias (menor al 3\%) en los sitios Laguna de los Pampas, Laguna Salalé, Laguna Chica, 


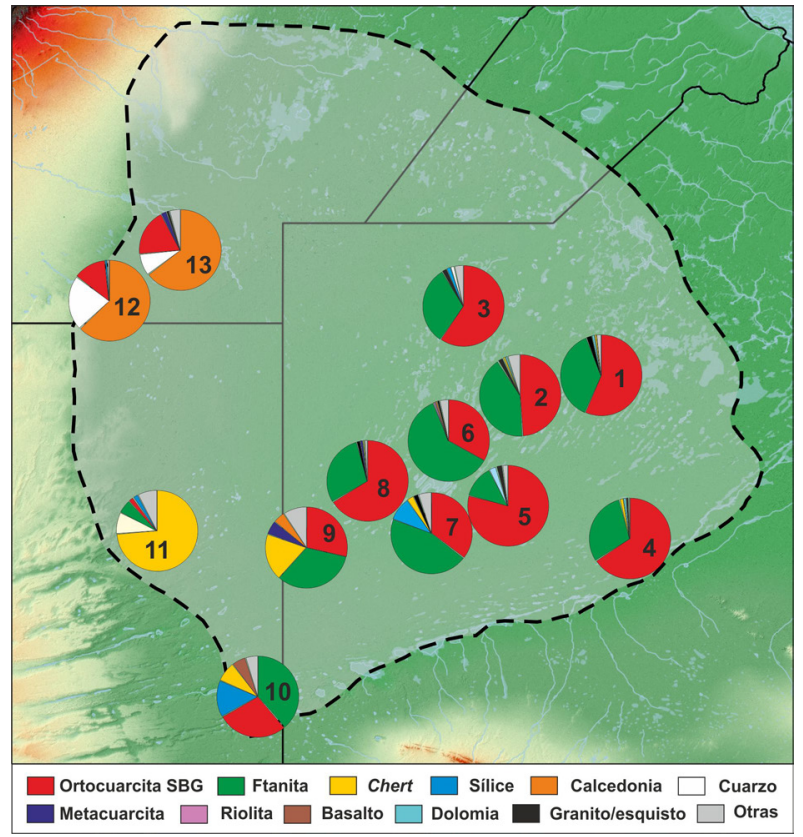

Figura 3. Frecuencia de las principales rocas representadas en los sitios del Campo de Dunas del Centro Pampeano.

Referencias: 1) Laguna de los Pampas; 2) Laguna Giaccone; 3) Laguna Salalé; 4) Laguna Cabeza de Buey 2; 5) Laguna Chica; 6) Laguna Las Tunas Grandes; 7) La Susana 1; 8) Huencú Nazar; 9) Médano Santa Clara; 10) Médano de Castilla; 11) Médanos de Peñín; 12) Laguna Tobarez; 13) La Angelita.

Figure 3. Frequencies of the main rocks represented in the Central Pampean Dunefields sites.

References: 1) Laguna de los Pampas; 2) Laguna Giaccone; 3) Laguna Salalé; 4) Laguna Cabeza de Buey 2; 5) Laguna Chica; 6) Laguna Las Tunas Grandes; 7) La Susana 1; 8) Huencú Nazar; 9) Médano Santa Clara; 10) Médano de Castilla; 11) Médanos de Peñín; 12) Laguna Tobarez; 13) La Angelita.

Huencú Nazar y Laguna Giaccone, entre otros (Figura 3). Una de las posibles explicaciones es la mayor cercanía del sitio Médano Santa Clara a los afloramientos del monte xerófilo de la subregión Pampa Seca, como por ejemplo la Meseta del Fresco, Laguna El Carancho y el Valle de Daza (Figura 1). En la mayoría de los sitios del centro-este de la provincia de La Pampa (e.g., Médano de Peñín, Laguna de Paisani, Laguna del Fondo y Laguna de Montoya) se registra un predominio del chert (Figura 3; Carrera Aizpitarte, 2014). Otra explicación que se debería explorar a futuro es la temporalidad de las ocupaciones, aunque para esto existen pocos datos de sitios en estratigrafía con un buen control cronológico. El Médano Santa Clara pudo ser ocupado durante la parte final del Holoceno tardío y en momentos de contacto HispanoIndígena dada la asociación contextual (Madrazo, 1972). Esta idea se vincula con el sitio Hangar, localizado en la parte occidental del área Interserrana (partido de Gral. Lamadrid), que posee un contexto fechado para el Holoceno tardío final (entre 1335 y 835 años C14 AP) y donde se registró un 10\% de representación de chert (Barros et al., 2018), lo cual podría indicar una mayor circulación de esta roca en este lapso.

\section{Obtención de rocas y actividades de talla}

Las características del conjunto analizado permiten establecer tendencias generales sobre la gestión de las rocas, particularmente la obtención de las materias primas, las actividades de talla realizadas en el sitio y el instrumental confeccionado. En líneas generales, no se observan diferencias notables entre las categorías artefactuales representadas para cada materia prima, particularmente aquellas mayoritarias. Los núcleos recuperados son preferentemente mediano pequeños y mediano grandes, no superando en ningún caso los $5 \mathrm{~cm}$ de largo (Figura $2 \mathrm{~m}-\mathrm{p}$ ). En dos de los núcleos pudieron establecerse las formas base sobre las cuales se trabajó, consistiendo en una lasca indeterminable y un nódulo de ftanita. Sólo cuatro núcleos de ftanita presentan remanente de corteza (menos del 50\% de la superficie). En cuanto a las operaciones de talla, la mayoría de ellos presentan más de dos plataformas. A partir del ancho y ángulo de golpe de la boca de los negativos de lascados, se pudo establecer el empleo de diferentes técnicas de talla como la percusión directa dura, blanda y con apoyo para la obtención de los soportes. La dirección y disposición de los negativos de lascados en cada núcleo indica que la extracción de lascas se llevó a cabo con diversos métodos (Santos Valero, 2017), como el unipolar corto (núcleos piramidales regulares), el bipolar (núcleos bipolares), el discoidal bifacial (poliédricos), así como la combinación de los métodos centrípeto y unipolar corto para el aprovechamiento óptimo del núcleo (núcleos globulares). Esto se traduce, a su vez, en una gran cantidad de núcleos agotados y con evidencias de la rotación de sus plataformas.

Con respecto a los desechos, en todas las materias primas predominan los pequeños, espesos y sin corteza. Si bien se observa variabilidad de tipos de lascas, en todas las rocas las más frecuentes son las angulares e indeterminables, indicando el predominio de etapas avanzadas de la talla. Aquellas lascas de las primeras etapas de la reducción (e.g., primarias y secundarias, con más del $50 \%$ de la cara dorsal con cubierta de corteza y talones naturales corticales) están escasamente representadas. La diversidad de talones identificados sugiere nuevamente el uso de diferentes técnicas de talla entre las que pueden mencionarse la percusión directa dura y blanda, así como la presión. Estas distintas técnicas responderían a diferentes etapas de la talla, predominando aquellas intermedias y finales (Espinosa, 1995; Magne, 1989).

Finalmente, los instrumentos presentan una gran diversidad tipológica, donde los instrumentos compuestos y raspadores son los más frecuentes (Tabla 4). Es destacable la presencia de fragmentos de artefactos asociados a la molienda, así como una bola de boleadora. En la colección del museo de Salliqueló se encuentran depositados 
artefactos de molienda de grandes dimensiones (morteros y manos) y boleadoras (ver Madrazo, 1972: Fig. 11). Por otro lado, dentro del conjunto se destacan las puntas de proyectil triangulares apedunculadas manufacturadas en chert, ortocuarcita y ftanita (Figura $2 \mathrm{j}-\mathrm{I}$ ). La presencia de una preforma en chert indica la confección de algunas de estas puntas en el sitio. Las piéces esquillées (sensu Tixier, 1963) recuperadas, por su parte, son resultantes del empleo del método bipolar (Figura $2 g-h$ ). Si bien, en líneas generales, los tamaños de los instrumentos coinciden con los de los desechos y núcleos recuperados, en el caso de las ortocuarcitas, metacuarcitas y riolitas (Tabla 3), se registran instrumentos cuyos tamaños sobrepasan a los artefactos anteriormente mencionados.

Todas estas características permiten proponer posibles modos de obtención para cada materia prima. En este sentido, las ftanitas podrían haber sido recolectadas directamente en las fuentes (Binford, 1979), donde aparecen bajo la forma de nódulos de diversas dimensiones, y ser trasladadas hasta el sitio ya sea como nódulos, núcleos sobre lascas con remanentes de corteza y gran diversidad de lascas como formas base. La ortocuarcita también pudo ser el resultado del aprovisionamiento directo en las fuentes (Messineo y Barros, 2021). Sin embargo, el registro de esta roca comprende núcleos, lascas internas y externas, así como un instrumento sobre un nódulo. Debido a ello, la forma de obtención de esta materia prima es difícil de establecer, pudiéndose tratar tanto del traslado de nódulos, lascas nodulares y/o núcleos preparados. Si bien la muestra de dolomía silicificada es pequeña y poco diagnóstica, pudo ser obtenida durante las mismas tareas de recolección en las fuentes de ftanitas, ya que las canteras se localizan a corta distancia en el sector noroccidental de Tandilia (Messineo y Barros, 2015).

Con respecto a la ortocuarcita, es importante mencionar la presencia de un cache en el sitio Médano Santa Clara compuesto por raederas, bifaces y un núcleo de grandes dimensiones (Madrazo, 1972: Fig. 13). En el CDCP y en otros sectores de la región pampeana alejados de los afloramientos rocosos se han identificado algunos caches de ortocuarcita, como por ejemplo en el partido de Trenque Lauquen (Sanguinetti de Bórmida, 1966; Scheifler, 2019; Scheifler et al., 2017). En este caso, se observa la generación de reservorios de materias primas por parte de los grupos cazadores-recolectores, a modo de site furniture (Kuhn, 2004), en sectores del paisaje carentes de estos recursos y que se localizan a grandes distancias de las fuentes.

El registro de chert se compone de desechos e instrumentos. Entre los primeros, si bien se cuenta con una lasca primaria, predominan aquellas sin corteza y de etapas avanzadas de la talla. A su vez, se han identificado dos instrumentos realizados directamente sobre plaquetas de esta materia prima. La alta frecuencia de puntas de proyectil sobre esta roca (Figura 2l), incluida una preforma, es un rasgo destacable ya que, hasta el momento, en la mayoría de los sitios del CDCP de la provincia de Buenos Aires las puntas de proyectil se habían registrado en ftanita y ortocuarcita (Messineo y Barros, 2021; Messineo et al., 2019b; Scheifler, 2019). Este conjunto no permite establecer formas claras de aprovisionamiento del chert, pudiendo ser adquirido bajo la forma de plaquetas, instrumentos y/o artefactos mayoritariamente descortezados que permitiesen la obtención de formas base. A su vez, la evidencia recuperada no es concluyente para establecer si el aprovisionamiento fue directo o indirecto, pero sí que se trataría de rocas procedentes del monte xerófilo de la subregión Pampa Seca.

Con respecto a las rocas procedentes de Ventania, la metacuarcita se encuentra presente en el registro como un núcleo agotado, lascas internas de diversos tipos y algunas externas (primarias y secundarias, con talones naturales corticales) e instrumentos. Respecto de estos últimos, algunos de ellos presentan dimensiones mayores al resto del conjunto artefactual. Debido a ello, se considera que esta roca pudo trasladarse bajo la forma de núcleos y/o instrumentos con reserva de corteza. Un panorama similar ocurre con la riolita de la que se identificaron desechos e instrumentos, algunos de estos últimos de mayores dimensiones que los primeros, por lo que debió llegar al sitio como algún artefacto en avanzado estado de reducción y/o instrumentos terminados. El registro de las areniscas cuarzosas comprende fragmentos de instrumentos de molienda desarrollados sobre plaquetas. Dado que esta materia prima se presenta naturalmente bajo la forma de plaquetas espesas a poco espesas (Santos Valero, 2017), es posible que su aprovisionamiento se haya dado de esta manera. Al igual que con el chert, los datos no permiten establecer si se produjo el aprovisionamiento directo de las rocas de Ventania.

La calcedonia aparece en el registro como desechos e instrumentos que no superan en ningún caso los $3 \mathrm{~cm}$ de longitud, y con escasos restos de corteza. Esto podría sugerir que su obtención pudo darse a partir de artefactos parcialmente descortezados provenientes del sitio Loma de los Pedernales, donde esta materia prima se presenta bajo la forma de nódulos dispersos en la superficie de la cantera (Heider, 2015). Aunque la evidencia recuperada no es concluyente para establecer si el aprovisionamiento fue directo o indirecto; se plantea que la escasa presencia de esta roca, la alta frecuencia de instrumentos y la distancia a las fuentes hace pensar que su adquisición se habría producido, posiblemente, mediante el intercambio entre grupos cazadores-recolectores que ocupaban diferentes territorios.

Finalmente, es interesante destacar algunos aspectos del conjunto que sugieren una optimización de todas 
las materias primas. En este sentido, se identificaron instrumentos compuestos y raspadores que no sobrepasan los 1,6 cm de longitud, así como la presencia de instrumentos con filos embotados $(35,1 \%)$ y reactivados (5,6\%). En esta misma línea, la mayoría de los núcleos presentaban evidencias de la rotación de sus caras durante la talla (45,5\%), así como el agotamiento de las plataformas de extracción (54,5\%). Sumado a ello, la presencia de núcleos bipolares y piéces esquillées también sugiere el aprovechamiento óptimo de las materias primas que debieron ser trasladadas desde largas distancias.

\section{Conclusiones}

Las investigaciones realizadas permitieron obtener información novedosa sobre los materiales líticos del sitio Médano Santa Clara, un conjunto recolectado en la década de 1970 por Madrazo. Se pudieron establecer las fuentes de procedencia de los recursos líticos, las formas base transportadas y las actividades de talla desarrolladas por los cazadores-recolectores que ocuparon el sitio. Dado que se trata de una de las ocupaciones en el sector sudoccidental del CDCP, el análisis del conjunto lítico permitió, por un lado, generar tendencias preliminares acerca de la gestión de las rocas en este sector del área, así como también observar diferencias con aquellos sitios localizados en el resto del CDCP. En este sentido, al comparar las frecuencias de representación de las rocas entre el Médano Santa Clara y otros sitios del CDCP, se observa claramente un uso diferencial de las materias primas explotadas, particularmente la ftanita, la ortocuarcita del Grupo Sierras Bayas y el chert. De esta manera, la información del sitio Médano Santa Clara complejiza el entendimiento de la gestión de rocas en el CDCP efectuada por los grupos cazadores-recolectores que lo habitaron.

Olavarría, 24 de Febrero 2021

\section{Agradecimientos}

Queremos expresar nuestro agradecimiento a los revisores de este artículo, cuyas sugerencias permitieron mejorar la lectura del manuscrito. Las investigaciones llevadas a cabo en el CDCP están financiadas con subsidios de la ANPCyT (PICT 2018-02154), el CONICET (PIP Nº414) y National Geographic Society (NGS-50543R-18). Este artículo es una producción de la UE INCUAPA-CONICET, Facultad de Ciencias Sociales (UNICEN).

\section{Bibliografía}

Andrefsky, W. (1998). Lithics: macroscopic approaches to analysis. Cambridge University Press: Cambridge.

Aschero, C. A. (1975). Ensayo para una clasificación morfológica de artefactos líticos. Ms. Informe al
CONICET. Facultad de Filosofía y Letras, Universidad de Buenos Aires: Buenos Aires.

Aschero, C. A. (1983). Ensayo para una clasificación morfológica de artefactos líticos. Revisión. Ms. Guías de cátedra. Ergología y Tecnología. Facultad de Filosofía y Letras. Universidad de Buenos Aires: Buenos Aires.

Aschero, C.A., y Hocsman, S. (2004). Revisando cuestiones tipológicas en torno a la clasificación de artefactos bifaciales. En A. Acosta, D. Loponte y M. Ramos (Eds.), Temas de Arqueología, Análisis lítico, (pp. 7-25). Luján: Universidad Nacional de Luján.

Barros, M.P., Messineo, P.G. y Colantonio, M.J. (2015). Chert quarries and workshops in the Humid Pampa subregion: New contributions on exploitation techniques and circulation through study of chaînes opératoires. Quaternary International 375, 99-112.

Barros, M.P., Heider, G., Álvarez, M.C., Kaufmann, C. y Bellinzoni, J. (2018). First results of the hunter-gatherer weapon system studies in the middle basin of the Salado creek (Pampas Region, Argentina). Journal of Lithic Studies 5 (2). https://doi.org/10.2218/jls.2785

Barros, M.P., Álvarez, M.C., Kaufmann, C.A., GómezPeral, L., Rafuse, D.J. y Politis, G.G. (2021). Una nueva cantera de cuarcita en el extremo occidental de Tandilia. En C.A. Quintana, M.C. Álvarez, G.F. Bonnat, D.L. Mazzanti, M.P. Barros, V. Puente y M. Bonomo (Comps.) Resúmenes del IX Congreso de Arqueología de la Región Pampeana Argentina, (pp. 139). Mar del Plata: Facultad de Humanidades, Universidad Nacional de Mar del Plata.

Bayón, C., Flegenheimer, N., Valente, M. y Pupio, A. (1999). Dime cómo eres y te diré de dónde vienes: procedencia de rocas cuarcíticas en la región Pampeana. Relaciones de la Sociedad Argentina de Antropología, XXIV, 187-232.

Bellelli, C., Guráieb, A. y García, J. (1985-1987). Propuesta para el análisis y procesamiento por computadora de desechos de talla lítica (DELCO-Desechos líticos computarizados). Arqueología Contemporánea, 2 (1), 36-53.

Berón, M.A. (2006). Base Regional de recursos minerales en el occidente pampeano. Procedencia y estrategias de aprovisionamiento. Relaciones de la Sociedad Argentina de Antropología, XXXI, 47-88.

Berón, M.A., Carrera Aizpitarte, M. y Páez, F. (2015). Arqueología en el área de Valles Transversales (provincia de La Pampa, Argentina). Caracterización y tendencias de los conjuntos arqueológicos. Implicancias sociales en 
la construcción del paisaje. Relaciones de la Sociedad Argentina de Antropología, XL (2), 549-587.

Binford, L. (1979). Organization and formation processes: Looking at curated technologies. Journal of Anthropological Research, 35, 255-273.

Bonomo, M. y Prates, L. (2014). La explotación de depósitos secundarios de rodados en el curso medio del río Negro y el litoral marítimo pampeano. En P. Escola y S. Hocsman (Eds.), Artefactos líticos, movilidad y funcionalidad de sitios en Sudamérica. Problemas y Perspectivas, (pp. 1-18). Oxford: BAR International Series.

Bórmida, M. (1960). Investigaciones paletnológicas en la región de Bolívar, Provincia de Buenos Aires. Anales de la Comisión de Investigaciones Científicas de la Provincia de Buenos Aires, 1, 190-283.

Bórmida, M. (1962). El Epiprotolítico epigonal de la Pampa Bonaerense. (La industria de La Montura, Pdo. de Bolívar, Prov. de Buenos Aires). Jornadas Internacionales de Arqueología y Etnología, 2, 113-133.

Cabral, M., Hurtado, M., Muntz, D. y Sánchez, C. (2014). Cartografía temática como base para el ordenamiento territorial partido de Salliqueló, provincia de Buenos Aires. En M. Miraglia, N. Caloni y G.D. Buzai (Eds.), III Congreso Internacional de Ordenamiento Territorial y Tecnologías de la Información Geográfica, (pp. 7-29), Buenos Aires.

Carrera Aizpitarte, M. (2014). Estudio de las estrategias de aprovisionamiento lítico en las áreas Curacó, Bajos sin Salida, Valles Transversales y Centro-este (provincia de La Pampa, Argentina). (Tesis doctoral). Facultad de Ciencias Sociales, Universidad Nacional del Centro de la Provincia de Buenos Aires, Olavarría, Argentina.

Carrera Aizpitarte, M.P., Berón, M.A. y Blasi, A. (2015). Study of siliceous outcrops of Meseta del Fresco, La Pampa, Argentina. Quaternary International, 375, 2743.

Catella, L. (2014). Movilidad y Utilización del Ambiente en Poblaciones Cazadoras-Recolectoras del Sur de la Región Pampeana: la Cuenca del Arroyo Chasicó como Caso de Estudio. (Tesis doctoral). Facultad de Ciencias Naturales y Museo, Universidad Nacional de La Plata, La Plata, Argentina.

Catella, L., Moirano J. y Oliva F. (2010). Disponibilidad de materias primas líticas y su importancia para el análisis del uso del espacio y la organización de la tecnología en sociedades cazadoras-recolectoras. En Mamül Mapu: pasado y presente desde la arqueología pampeana, editado por M. Berón, L. Luna, C. Montalvo, C. Aranda y M.
Carrera Aizpitarte, pp. 215-229, vol. II. Libros del Espinillo, Ayacucho, Buenos Aires.

Catella, L., Manassero, M., Moirano, J. y Oliva, F. (2013). Nuevos aportes al estudio del aprovisionamiento de cuarcita en la Región Pampeana, Argentina. Cuadernos del Instituto Nacional de Antropología y Pensamiento Latinoamericano, Series Especiales, 1 (2), 200-215.

Charlin, J. (2002). Aprovisionamiento de Materias Primas Líticas en el N.O. de la Provincia de la Pampa a Fines del Siglo XIX. En Del Mar a los Salitrales. Diez mil Años de Historia Pampeana en el Umbral del Tercer Milenio, editado por D. L. Mazzanti, M. A. Berón y F. W. Oliva, pp. 205-218. Sociedad Argentina de Antropología y Facultad de Humanidades, Laboratorio de Arqueología, Universidad Nacional de Mar del Plata, Mar del Plata.

Colombo, M. (2011). Modalidades de abastecimiento de rocas entre los cazadores y recolectores pampeanos. Intersecciones en Antropología, 12, 231-243.

Espinosa, S. (1995). Dr. School y Monsier Fleur: de Talones y Bulbos. Cuadernos del Instituto Nacional de Antropología y Pensamiento Latinoamericano, 16, 315- 328.

Gavilán, M.E., Scarafía, G., Tamburini, D., y Carletti, S. (2004). Análisis tecnotipológico de los desechos de talla lítica del sitio Laguna Las Tunas Grandes. Trenque Lauquen, Provincia de Buenos Aires. En C. J. Gradín y F. Oliva (Eds.), La Región Pampeana -Su pasado arqueológico-, (pp. 389-399). Rosario: Laborde Editor.

Heider, G. (2015). Los Pueblos Originarios en el Norte de Pampa Seca. Una Mirada Arqueológica a los Cazadores Recolectores del Sur de las Provincias de Córdoba y San Luis, Argentina. (Tesis doctoral). Facultad de Filosofía y Humanidades, Universidad Nacional de Córdoba, Córdoba, Argentina.

Heider, G. y Demichelis, A. (2015). Loma de los Pedernales, a local raw material source in the North of Pampa Seca, Argentina. Quaternary International, 375, 3-12.

Madrazo, G. (1972). Arqueología de Lobería y Salliqueló (Pcia. de Buenos Aires). Etnia, 15, 1-18.

Madrazo, G.B. (1973). Síntesis de arqueología Pampeana. Etnía, 17, 13-25.

Magne, M. (1989). Lithic Reduction Stage and Assemblage Formation Processes. En D.S. Amick y R.P. Mauldin (Eds.), Experiments in Lithic Technology, (pp. 15-31). Oxford: BAR, International Series 528. 
Martínez, G. y Santos Valero, F. (2020). Petrographic thin sections and exotic rocks provenience among huntergatherers societies in the eastern Pampa-Patagonia transition (lower basin of the Colorado river, Argentina). Archaeometry, 62 (3), 493-505.

Martínez, O.A., Rabassa, J. y Coronato, A. (2009). Charles Darwin and the first scientific observations on the Patagonian shingle Formation (Rodados Patagónicos). Revista de la Asociación Geológica Argentina, 64 (1), 90-100.

Mazzanti, D.L. (2005). La institucionalización de la arqueología desde Olavarría. Andes, 16, 1-14.

Messineo, P.G. y Barros, M.P. (2015). Lithic raw materials and modes of exploitation in quarries and workshops from the center of the Pampean grassland of Argentina. Lithic Technology, 40 (1), 3-20.

Messineo, P.G. y Barros, M.P. (2021). Huntergatherer mobility and territories in the dunefields of center Argentina. Journal of Lithic Studies, 8 (1) ,1-19. https://doi.org/10.2218/jls.4313

Messineo, P.G., González, M.E., Álvarez, M.C. y Pal, N. (2018). Las ocupaciones humanas en la localidad arqueológica Laguna de los Pampas (Campo de Dunas del Centro Pampeano, Argentina) durante el Holoceno. Latin American Antiquity, 29 (4), 736-753.

Messineo, P.G., Scheifler, N.A., Álvarez, M.C., González, M.E., Pal, N., Barros, M.P. y Politis, G.G. (2019a). A model of human occupation in the Central Pampean Dunefields of Argentina. PaleoAmerica: A Journal of Early Human Migration and Dispersal, 5 (4), 378-391.

Messineo, P.G., Barros, M.P., Pal N. y Scheifler, N.A. (2019b). Transporting rocks to an empty environment of lithic materials. The case of the Central Pampean Dunefields (Argentina). Journal of Archaeological Science: Reports, 25, 433-446.

Messineo, P.G, Tonello, M.S., Stutz, S., Tripaldi, A., Scheifler, N.A., Pal, N., Sánchez Vuichard, G. y Navarro, D. (2019c). Human occupations and related environment-climate during the Middle and Late Holocene in central Pampas of Argentina. The Holocene, 29 (2), 244-261.

Oliva, F., Ávila, J.D., Gallego, M. y Algrain, M. (2004). Investigaciones arqueológica en la Laguna Salalé (partido de Florentino Ameghino, provincia de Buenos Aires). Una aproximación al uso de los recursos críticos. En C. J. Gradín y F. Oliva (Eds.), La Región Pampeana -Su pasado arqueológico (pp. 377-387). Rosario: Laborde Editor.
Oliva, F., Panizza, M.C., Catella, L., Moirano, J., Morales, N., Algrain, M., Devoto, G., Iannelli, L., Oliva, C., Pereyra, B. y Sfeir, A. (2015). La construcción del pasado arqueológico en diferentes sectores del Área Ecotonal Húmedo-Seca Pampeana. Investigación y extensión desde el Centro de Estudios Arqueológicos Regionales. Revista de Antropología del Museo de Entre Ríos, 1 (2), 91-102.

Sanguinetti de Bórmida, A. (1966). Las industrias de Trenque Lauquen (Provincia de Buenos Aires). Acta Prehistórica, 5-7, 72-94.

Santos Valero, F. (2017). La gestión de rocas a través del tiempo: aportes al estudio de la tecnología lítica durante el Holoceno medio y tardío en el valle inferior del río Colorado (provincia de Buenos Aires). (Tesis doctoral) Facultad de Ciencias Sociales, Universidad Nacional del Centro de la Provincia de Buenos Aires, Olavarría, Argentina.

Scheifler, N.A. (2019). Ecología y Subsistencia de los Cazadores-recolectores en el Campo de Dunas del Centro pampeano. Sociedad Argentina de Antropología: Buenos Aires.

Scheifler, N.A., Messineo, P.G. y Antiñir, A.A. (2017). Cazadores-recolectores en el Sistema Lagunar Hinojo-Las Tunas (región pampeana, área Oeste) durante el Holoceno temprano/medio y tardío. Primeros resultados de las investigaciones arqueológicas. Comechingonia. Revista de Arqueología 21, (1), 287-314.

Tapia, A., Salvino, A, y Aguerre A.M. (2020). Chadilauquen y Neicorehue, dos asentamientos lagunares con cerámica en el nordeste de la Pampa Seca. Relaciones de la Sociedad Argentina de Antropología, XLV (2), 323-353.

Tixier, J. (1963). Typologie de l'Épipaléolithique du Maghreb. Paris: Arts et métiers graphiques.

Zárate, M. y Tripaldi, A. (2012). The aeolian system of central Argentina. Aeolian Research, 3, 401-417. 
F. Santos Valero y P. G. Messineo | Revista del Museo de Antropología 14 (3): 47-60 | 2021

DOI: http://doi.org/10.31048/1852.4826.v14.n3.32273 